\title{
Improving Information Technology Infrastructure Library Service Delivery Using an Integrated Lean Six Sigma Framework: A Case Study in a Software Application Support Scenario
}

\author{
Anil Kumar Raghavan Pillai,1,2, Ashok Kumar Pundir ${ }^{3}$, L. Ganapathy \\ ${ }^{1}$ Marlabs Software Inc. (USA), Piscataway, USA \\ ${ }^{2}$ Symbiosis International University, Pune, India \\ ${ }^{3}$ National Institute of Industrial Engineering (NITIE), Mumbai, India \\ Email: anilpillai kalampukattu@yahoo.co.in, pundir.ashok@gmail.com, \\ ganapathyl@gmail.com
}

Received 2 March 2014; revised 1 April 2014; accepted 8 April 2014

Copyright @ 2014 by authors and Scientific Research Publishing Inc. This work is licensed under the Creative Commons Attribution International License (CC BY). http://creativecommons.org/licenses/by/4.0/ (c) (1) Open Access

\begin{abstract}
Increasing competition in service businesses (eg: Information Technology, Healthcare, Education, Logistics, Distribution, Hospitality Financial and other services) is compelling corporates to adopt business improvement philosophies and methodologies for addressing customer demands for better quality service and organizational demands for improving the profit margins through cost reduction. Many companies around the world have already implemented Information Technology Infrastructure Library (ITIL) as a way to manage and control their Information Technology (IT) Departments more effectively. These companies are now willing to improve their ITIL processes in order to become even more efficient. Lean Six Sigma is a methodology that has been suggested as a means to resolve these problems, reducing costs and improving quality. Its application in the IT Services area is becoming increasingly popular among researchers and academicians and can be used to conduct these improvements. Despite the application of lean six sigma approaches to different contexts in the service sector, the application of Lean Six Sigma approaches in service delivery specific to Information Technology Service Management (ITSM) remains largely untested. The purpose of this paper is to implement Integrated Lean Six Sigma for Software application support services and evaluate the benefits of continual service improvement over ITIL.
\end{abstract}




\section{Keywords}

\section{Information Technology Infrastructure Library, Change Management, Configuration Management, Software Application Support, Lean Six Sigma}

\section{Introduction}

Information Technology (IT) organizations deliver a wide variety of services to the business. These services include application development, application support, application maintenance and infrastructure support. Increasingly; IT organizations are seeking to improve the quality of the services that they provide to the business. Nowadays, in service applications, the revenue growth potential of improving the speed and quality of service often overshadows the cost reduction opportunities [1]. However, services are frequently criticized for being delivered at a slow pace because there is too much waste in the service processes such that not only the costs of services are inflated but also service quality deteriorates. Moreover, one of the characteristics of service business is the heterogeneity [2]. This causes variations in the level of service to customers, and consequently results in poor service quality and customer's dissatisfaction. These service issues represent a huge opportunity to improve the service quality by increasing the speed of service delivery and reducing the variations in service level.

It is to be noted that the management issues in rendering of service is different from those in making of products. Process methodologies such as SEI-CMMI, and ISO/IEC 20000, and Agile focus on the development of software whereas the ITIL is a definitive approach that focuses exclusively on Software Service Management. ITIL defines a process methodology as one of the best management practice for continuous service improvement with a focus on improving quality, reducing costs, improving effectiveness and efficiency of IT services.

The introduction of formal ITIL processes into an organization can be a prolonged and expensive process. Many organizations upon completing their process implementation projects presume that the processes will go on forever. Often, that is not the case-without continual attention to the processes they almost surely will not stay abreast of the changing needs of the organization and process performance shortfalls will not be addressed. As Information Technology Infrastructure Library (ITIL) states, after implementing the processes, they must be continuously improved to steadily increase efficiency. Furthermore, business itself is not static, and IT processes must evolve at the same pace in order to effectively support it and remain aligned with it. However, conducting improvements is not easy [3] and recent ITIL literature suggest some methodologies that can be used to do so.

More recently, Lean Six Sigma has emerged as organizations strive to meet the quality objectives defined by their customers. It combines the principles of Lean with the best practices of Six Sigma. The result is a methodology that serves to improve processes, eliminate product or process defects and to reduce cycle times and accelerate processes. By combining the Lean Six Sigma quality methodology, IT service management (ITSM) will have the methodology and tools for measuring quality and improving processes. Adopting Lean Six Sigma principles also helps IT managers focus on their business strategy and customers, manage proactively based on facts, and reinforce collaboration across the enterprise.

In our present case, an empirical study is conducted for “Application Support” for an SAP implementation in a world class airline catering organization where Lean Six Sigma is administered over ITIL. To get an idea of scale of operations involved, this company offers airline catering, last mile provisioning, onboard retail solutions, serving 5 continents, 26 countries, 115 flight kitchens, 9600 flights per day, 220 million meals served every year, and 300 million passengers served annually providing world’s finest inflight experience.

In this paper, we present an application of Lean Six Sigma methodology, as a case for continuous improvement after implementing the ITIL processes for ITSM by conducting a practical study on software application support project and analyzing the benefits. The case study deals with the implementation of ITIL framework for service management and delivery for SAP application support. The study focusses on a case implementation of Lean Six Sigma for where Lean Six Sigma methodology is applied over ITIL process. Lean Six Sigma is used for continuous improvement of the customer satisfaction levels through improved reliability on a continuous basis.

This paper is structured as follows: the key attributes of ITIL, Lean, Six Sigma and Lean Six Sigma are dis- 
cussed independently. The integrated Lean Six Sigma framework in this empirical study is adopted from [4] for improving service quality of IT help-desk service. It makes the case for leveraging ITIL and Lean Six Sigma for ITSM, studies the benefits in terms of continuous improvement and discusses opportunities for future research and implications for management.

\section{Motivation for Using Lean Six Sigma for ITIL Service Delivery}

Modern day organizations heavily rely upon IT to enable them to achieve their company vision, business strategy and goals. Typical benefits to organizations using IT include:

- Radical change in the way they operate, communicate and do business.

- Develop and innovate, gain market advantage and differentiate themselves to their end customers.

- Drive increased productivity and efficiency, improve business processes, make cost savings, and increase sales and growth.

- Communicate with a larger, more global marketplace.

The quality of an organization's IT is reflected in its reputation and brand, and has direct impact upon its sales and revenue. The cost of IT is never insignificant, hence it is essential to get good value from IT investments, but often this value is not realized. For an IT investment to provide benefit, the resulting IT service must be well planned, well designed, well managed and well delivered.

Organizations are implementing ITIL for ITSM for creating quality standards to design, deliver and manage IT services to meet or exceed an agreed level of quality. It is important to keep improving the processes, always aiming to provide IT Services with higher quality and efficiency. On the other hand, IT departments can no longer be isolated silos in the organizations. They must be completely aligned with business in order not only to support it, but also to improve it [5]. Still, businesses are not static and so IT services cannot be static either, it needs to be adapted as a response to market needs and to exploit business opportunities that arise.

ITIL defines a framework of best practices for ITSM in the areas of application maintenance, application support and infrastructure support. It consists of a set of guidelines that specify what an IT organization should do based on industry best practices. It does not, however, define how to do it. For example, ITIL specifies that IT should allocate a priority for each incident that comes into the service desk, but it does not specify how to allocate those priorities. With ITIL, it is up to the IT staff to work out the details of process flow and create detailed work instructions in a way that is appropriate for their organization.

However ITIL does not provide a method for measuring quality or identifying and completing process improvement projects. Hence organizations are researching on aligning ITIL with other methodologies and frameworks for continuous improvement.

\section{Literature Review}

During their evolution, IT organizations typically mature through three stages: technology provider, service provider and strategic partner [6]. Research suggests that large enterprises spend an average of $73 \%$ of their IT budget on Application Support and Maintenance activities of existing system [7]. Clearly, ITSM presents high potential for cost savings in global enterprises

Good ITSM is essential to achieve business benefits from IT at an agreed and controlled cost. Without good ITSM, it is common for IT projects to fail or go well over budget at project stage, for on-going IT costs of ownership to spiral out of control, and for businesses to fail to achieve the benefits they expected [8].

Research in service quality has highlighted a parallel between the increasing cost and declining quality seen in services and the same trend previously observed in the manufacturing sector [9] [10]. Increasing customer demands, competitive pressures and rising operational costs are beginning to force a dramatic rethink of the management of operations in this area [11].

Reference [8] makes an argument contrary to the typical definition of software maintenance as: "the totality of activities required to provide cost-effective support to a software system". His view of totality thus encompasses activities in the pre-delivery stage in addition to the traditional emphasis on the post-delivery stage. His view includes planning for post-delivery operations, supportability and logistics determination in addition to post-delivery activities such as software modification, training, and help desk support. According to [8], the following functions should be specified within a software maintenance organization's charter: management, software modification, software configuration management, training, documentation support, user liaison and help desk, test- 
ing, quality assurance and technical assistance.

Organizations resort to research on usability of other proven frameworks or methodology to be adopted over the ITIL to achieve productivity improvements and cost reductions. There is evidence of frameworks, based on the Lean methodology, which can be used to guide ITIL processes optimization [12]. Attempts have also been made by integrating the Six Sigma quality methodology with ITSM to offer the methodology and tools for measuring quality and improving processes [13].

Studies also show the use of Lean Six Sigma in software application development in IT service organizations. Reference [4] proposed an integrated Lean Six Sigma methodology for service quality improvement, examined the rationale for the combination of the two disciplines and justified on theoretical basis. They also report an empirical study conducted for IT helpdesk service scenario to illustrate the deployment processes and the effectiveness of the methodology for service quality improvement. Our earlier study showed that application of Lean Six Sigma is a great tool for continuous improvement providing considerable cost-advantage and productivity in software application development [14].

There are empirical studies are effectively conducted on integrating ITIL with Lean philosophy for improving IT processes [12].

Reference [13] proposed a framework for improving ITSM by combining Six Sigma with ITIL processes in the e-services and mobile applications. Studies have reported compelling benefits in aligning ITIL with Six Sigma [13]. Based on the white paper by GE, on combining ITIL with Six Sigma, these two approaches are highly complementary and can be used in combination effectively to continually improve business processes [15].

\subsection{ITIL}

ITIL was developed by the British Government during the 1980s trying to increase efficiency, value and success in the delivery of programs and projects in the public sector. Over the years, ITIL became popular and, nowadays, its credibility is highly recognized. Its practices are aligned and have contributed to the ISO 20000 Service Management standard, the first international standard for ITSM [16].

ITIL is the most widely adopted guidance for ITSM worldwide. It is a non-proprietary best practice that can be adapted for use in all business and organizational environments. ITIL's value proposition centers on the IT service provider (internal IT or external supplier) understanding a customer's business objectives and priorities, and the role that IT services play in enabling these objectives to be met. ITIL adopts a 'lifecycle' approach to IT services, focusing on practices for service strategy, service design, service transition, service operation and continual service improvement [17].

\subsection{Aligning ITIL with Lean}

Lean is a methodology to organize, manage, develop and improve business processes with the aim of doing more with fewer resources. In the manufacturing world, Lean thinking is a predominant approach to evaluating and eliminating waste in operations; a tool for improving the efficiency of existing processes. Lean identifies time spent on non-value-added activities and time spent between value-added activities. It emerged after the World War II in Toyota's manufacturing environment, however, in the last few years, it has been applied in the services industry [18]. Organizations have found that Lean concepts apply very well to non-manufacturing processes, especially the service and support processes common to the IT function. The misuse or abuse of time is the principal source of waste in these processes, just as in the manufacturing context.

Lean is based on the principles of specifying value, mapping the value stream, enabling continuous flow, pull strategies and pursuing perfection. Following these principles enables quicker and more flexible processes allowing the delivery of services with higher quality and more value to the customer [19]. In this paper, the expression "value" is used to describe any feature or service for which the customers would be willing to pay for.

Lean can address a wide range of sources of waste in end-to-end manual or systemized transactional processes including:

- Overproduction-too many transactions in the process;

- Over processing - too much non value-added activity;

- Waiting - too much time between value-added activities;

- Ownership issues—usually, too many owners complicating the decision making process; 
- Unnecessary movement-too much movement between value-added activities;

- Underutilization of human resources - the skill set deployed is too narrow.

ITIL's strengths include its focus on service to the customer, process, and continuous improvement. On the downside, however, ITIL alone may present significant implementation challenges, including potentially significant time consumption. ITIL does not provide insight into gaining efficiencies, nor does it address the leadership issues of organizational change. Furthermore, the launch of an ITIL initiative can seem cumbersome and complex. At its most basic level, ITIL presents a box of best practices, or the characteristics of past successful processes. ITIL is also a top-down approach: the boss announces an organization wide reengineering of processes, and then every person in that organization must put in a lot of extra time working in various groups to redesign and redeploy all of their processes. This is why ITIL is challenging in some environments.

Lean as a process improvement discipline and ITIL as a process improvement framework neatly complement each other in the IT world. Lean ITSM applies the efficiencies of Lean to the principles of ITIL-based service management practices to improve and streamline all processes and to reduce the costs associated with the IT function. Lean and ITIL share a common goal: improvement of the processes involved in developing and providing IT services within an organization. This intent however is not enough for an organization that seeks to truly improve the IT services function as a means of supporting the overall mission. The ultimate process goal must be to lower the costs of managing the infrastructure. Lean ITSM can free up resources that can be used elsewhere.

\subsection{Combining ITIL with Six Sigma}

Reference [20] found that Six Sigma and TQM could complement each other in order to achieve organizational success and gain a competitive advantage. Although invented at Motorola, Six Sigma has been experimented with by Allied Signal and further perfected at General Electric (GE). Today, Six Sigma is also extensively applied to non-manufacturing processes. The savings from transactional, support, service and other non-manufacturing sectors are significant [21]. The Six Sigma principle is normally applied to create high quality performance while proving overall reliability to the customers. It follows the principle that when defects are removed, total quality is improved.

Methods, Tools \& Techniques are vital to the success of any Six Sigma project. Six Sigma can be accomplished using two key methodologies: Define-Measure-Analyse-Design-Verify (DMADV) and Define-Measure-Analyse-Improve-Control (DMAIC)—both inspired by Deming's Plan-Do-Check-Act Cycle. Every stage of a Six Sigma project recipe requires a mix of these methods, tools \& techniques.

The Six Sigma methodology that is most widely used is known as DMAIC for process improvement. DMAIC offers a structured and disciplined methodology for solving business problems and enables a business to achieve extremely low non-conformance rates [22]. The Six Sigma tool kit includes a variety of techniques, primarily from statistical data analysis and quality improvement. Many quality tools are descended from TQM; others are more recent and sophisticated [23]. New tools will continue to be selectively added from other disciplines, like operations research [24].

Continuous improvement is an integral part of the ITIL [25]. Integrating Six sigma will enable IT management in ITIL to use the tools and methodology defined in Six Sigma methodology [13]. Through adoption of Six Sigma principles in ITIL helps IT managers concentrate on their business strategy and customers, manage proactively based on facts, and strengthen collaboration across the enterprise [13].

\subsection{Combining ITIL with Lean Six Sigma}

Lean Six Sigma builds on the knowledge, methods and tools derived from decades of operational improvement research and implementation. Lean approaches focus on reducing cost through process optimization. Six Sigma is about meeting customer requirements and stakeholder expectations, and improving quality by measuring and eliminating defects. Lean Six Sigma approach draws on the philosophies, principles and tools of both. Lean Six Sigma primarily focusses operational improvement-refining existing processes to reduce costs, improve performance and provide better customer value. Lean Six Sigma drives transformational, sustainable bottom line results through the use of proven methodologies that increase process speed, eliminate waste, reduce variation and improve customer satisfaction [26].

Lean Six Sigma's goal is growth not just cost-cutting. Lean Six sigma is suitable for services as: 
- Service processes are usually slow and therefore expensive. Slow processes reduce quality, drive costs up and customer satisfaction down.

- Service processes are slow because there is far too much work-in-progress (WIP). Complexity increases WIP. Some WIP spends $90 \%$ of its time in in-boxes waiting to be worked [27].

- Usually $80 \%$ of the delay is caused by less than $20 \%$ of the activities [23].

- Most steps in a service process add no value in the eyes of the customer.

The future of effective IT management lies in a deliberate combination of process refinement approaches that unites the strengths of methodologies such as Lean Six Sigma with ITIL while taking into consideration whether the right portfolio of services is offered. Combining Lean Six Sigma with ITIL represents an important step toward the future of ITSM.

\section{Case Study: Overview of Lean Six Sigma Implementation}

After the text edit has been completed, the paper is ready for the template. Duplicate the template file by using the Save As command, and use the naming convention prescribed by your journal for the name of your paper. In this newly created file, highlight all of the contents and import your prepared text file. You are now ready to style your paper.

\subsection{Approach}

The present case concerns the application of Lean Six Sigma over ITIL framework for a software application support of packaged application implementation for one of the world's independent provider of catering and provisioning services for airlines and railroads. The case under discussion here is the L2 (Level 2/Tier 2) technical support for the SAP implementation of the systems for this corporate.

The case study addresses the ITIL framework implemented for the organization which is providing ITSM to the customer. Thereafter the Lean Six sigma methodology is applied on top of the ITIL framework. The case study also discusses the continuous improvement achieved through the application of Lean Six Sigma for ITSM. Finally the results are analyzed and the benefits are detailed for further research.

\subsection{Definitions}

Technical support is often subdivided into tiers, or levels, in order to better serve a business or customer base. The number of levels a business uses to organize their technical support group is dependent on a business' need as it depends on their ability to sufficiently serve the customers or users.

\subsubsection{Tier 1/Level 1 Application Support}

This is the initial support level responsible for basic customer issues. The responsibility of a Tier 1 specialist is to gather the customer's information and to determine the customer's issue by analyzing the symptoms and figuring out the underlying problem. The support team member's role is to identify what the customer is trying to accomplish so that time is not wasted on "attempting to solve a symptom instead of a problem." Once the underlying problem is established, the specialist can begin solving the problem. Tier 1 Technical support specialists in typically handle straightforward and simple problems while "using some kind of knowledge management tool where the readymade solutions are available [28].”

\subsubsection{Tier 2/Level 2 Application Support}

This is a more in-depth technical support level as the team is more experienced and knowledgeable on a particular product or service. The role involves administrative level support, and various advanced technical troubleshooting and analysis methods. Technicians in Tier 2 team are responsible for assisting Tier 1 personnel in solving basic technical problems and for investigating escalated issues by confirming the validity of the problem and seeking for known solutions related to these more complex issues. However, prior to the troubleshooting process, the technician has to review the work order to see what has already been accomplished by the Tier 1 technician and the effort spent by the technician on this issue with the particular customer. This review is important in meeting both the customer and business needs and it allows the technician to prioritize the troubleshooting process and properly manage his or her time. If a problem is new and/or personnel from this group cannot de- 
termine a solution, the technician is responsible for raising this issue to the Tier 3 technical support group [8].

\subsubsection{Tier 3/Level 3 Application Support}

This is the highest level of support in a three-tiered technical support model. The technicians in Tier 3 are responsible for handling the most difficult or advanced problems which involves expert level troubleshooting and analysis methods. These individuals are experts in their fields and are responsible for assisting both Tier 1 and Tier 2 personnel in addition to the research and development of solutions to new or unknown issues. Tier 3 technicians have the same responsibility as Tier 2 technicians in reviewing the work order and assessing the time already spent with the customer so that the work is prioritized and time is efficiently utilized. The Tier 3 technician will have to work with the customer to solve the problem. Upon encountering new problems; however, Tier 3 personnel must first determine whether or not to solve the problem and may have to discuss with the customer to plan and manage the time needed to troubleshoot the issue and find a solution. In some instances, an issue may be so problematic which may turn out to be a show-stopper and resolution may impact the production. Such extreme problems are also sent to the original developers for in-depth analysis. Once it is determined that a problem can be solved, this team is responsible for designing and developing one or more solutions, evaluating these solutions in a test environment, and implementing the best solution to the problem. Once the solution is verified, it is delivered to the customer and made available for future troubleshooting and analysis [29].

\subsection{ITIL V3 Process Implementation}

For the case under study, the Standard Operating Procedure is derived through ITIL. ITIL V3 implementation has five distinct phases.

- Service Strategy: Determine requirements and which IT services should be provided;

- Service Design: Design, create or change services and service management processes to meet business requirements;

- Service Transition: Validate the utility and warranty of services and transition them into the live environment

- Service Operation: Provide the services and support in an efficient and effective manner;

- Continual Service Improvement: Ensure that the services continually address future needs.

\subsubsection{Service Strategy}

The Scope of the study is to provide Level 2 Application Supportfor SAP R/3 and SAP Business Warehouse (BW) for the following business processes:

- Order to Cash (OTC);

- Purchase to Pay (P2P);

- Finance \& Product Costing;

- Production Planning (MRP).

The SAP functional modules covered for this support are:

- Sales and Distribution (SD);

- Material Management (MM);

- Finance and Controlling (FICO);

- Production Planning (PP);

- Business Warehouse.

The main focus of the application support would be to identify the actual causes for an application break down, what the support team would do/handle in order to diagnose them, the typical corrective solution or work around for such a problem.

\subsubsection{Service Design}

The level 2 support is provided to the SAP functional modules covered in Service strategy based on the criticality for the business is for

- SD: 24 hours $\times 5$ days and 16 hours $\times 2$ days;

- MM: 24 hours $\times 5$ days and 16 hours $\times 2$ days;

- FICO: 20 hours $\times 7$ days;

- PP: 20 hours $\times 7$ days; 
- BW: 20 hours $\times 5$ days.

Table 1 provides the shift timings for various Time zones for the operations as part of the service design.

If there is an SAP application problem, a service desk ticket is to be raised with the L1 Support Desk. If the L1 Support Desk support desk finds that the ticket needs L2 support intervention, then the ticket is transferred to the SAP L2 support team.

Based on the shift timings, to support coverage for all the functional modules, the effort is estimated and the team size has been arrived at as given in Table 2 to meet the Service level Agreements given in Table 3 as part of the contract signed with the customer for this service delivery.

\subsubsection{Service Transition}

Service Transition is the phase where new or changed services are transitioned into Service Operations. It is important to take into consideration on controlling the risks of service failure and business disruption during this phase. Activities performed within this phase include:

- Capacity planning, estimating and identifying the resources needed to package, build, test, and deploy a release into production;

- Evaluating the service capability and risk profile prior to release;

- Creating repeatable build and installation mechanisms that can be used to deploy releases into test and production environments;

- Ensuring that services can be managed, operated and supported in accordance with requirements established in Service Design.

For the current case under study, the service transition is implemented for the SAP application support undertaken. There are four processes included in the Service transition:

Table 1. Shift timings.

\begin{tabular}{cccc}
\hline Time Zone/Region & Shift-1 & Shift-2 & Shift-3 \\
\hline India (IST-Indian Standard Time) & 12:00 PM to 8:00 PM & 8:00 PM to 4:00 AM & 4:00 AM to 12:00 PM \\
(APAC) & 2:30 PM to 10:30 PM & 10:30 PM to 6:30 AM & 6:30 AM to 2:30 PM \\
(EMEA-Central European Time) & 8:30 AM to 4:30 PM & 4:30 PM to 12:30 AM & 12:30 PM to 8:30 AM \\
Eastern Time (USA) & 2:30 AM to 10:30 AM & 10:30 AM to 6:30 PM & 6:30 PM to 2:30 AM \\
\hline
\end{tabular}

Table 2. Support coverage and initial team size.

\begin{tabular}{cccc}
\hline Module & Coverage & Shifts & Team Size \\
\hline SD/MM & $24 \times 5$ weekdays & $1,2 \& 3$ & 14 \\
PP & $16 \times 2$ weekends & $1 \& 2$ & 9 \\
FI/CO & $16 \times 7$ & $1 \& 2$ & 6 \\
ABAP & $16 \times 5$ & $1 \& 2$ & 4 \\
\hline
\end{tabular}

Table 3. Service level agreement (SLA).

\begin{tabular}{cccc}
\hline Ticket Type (Priority) & Ticket Definition & Response Time & Resolution Time \\
P1 & Critical & 30 minutes & 3 hours \\
P2 & High & 1 hour & 3 hours \\
P3 & Medium & 8 hours & 5 days \\
P4 & Low & & \\
\hline
\end{tabular}




\section{1) Change Management}

The Change management process begins with the initial user request for change. An assessment of risk must be completed on any Change prior to its approval. The changes can be a Standard Change, Emergency change or an Outage.

Table 4 provides typical activities that would be performed and also highlights the responsibilities of the various participants in order to ensure smooth operations.

A standard change is a scheduled change. Emergency change is any change that has a high level of urgency. Emergency change must have a valid business justification and must receive approval from IT Manager. This change need not wait for Change control board approval for its implementation.

The Change management process defined and used in the current case study is as follows.

- All the change management tickets will be handled through a software configuration management and defect tracking tool named JIRA.

- Business user/Super User/ raises a change request in consultation with the Teams on the tool.

- Assigns it to the Module lead, Module lead approves the request and assigns it to L2 functional member.

- L2 Functional member reviews the requirements and prepares a Functional specification (FS).

- FS will be attached to the tool and sends it to L2 technical team for feasibility check and effort estimation.

- Will be sent to L3 technical team for development approval.

- On Approval, technical team will do coding and unit testing, Promote the changes to Quality environment.

- Will be assigned to L2 functional team for Unit testing in Quality Environment.

- On successful testing L2 functional team will assign it to the requestor/L3 team member for User Acceptance Testing (UAT) along with the Test script and test results.

- On successful UAT, L2 team creates a technical spec, peer review check list, TP approval check list and sends it to L3 technical team for TP creation approval.

- On Approval L2 technical team creates a Transport proposal to move the changes to Production Environment.

- L3 functional team member approves the Transport proposal and changes will be moved to production through a prescheduled periodic job.

Table 4. Typical activities and responsibilities.

\begin{tabular}{|c|c|c|c|c|c|}
\hline \multirow{2}{*}{ No } & \multirow{2}{*}{ Snap shot of Typical Tasks/Activities } & \multirow{2}{*}{$\begin{array}{c}\text { By L2 Team } \\
\text { ACT }\end{array}$} & \multirow{2}{*}{$\begin{array}{c}\text { By Customer } \\
\text { CLOSE }\end{array}$} & \multirow{2}{*}{$\begin{array}{l}\text { Deliverables } \\
\text { Responsible }\end{array}$} & \multirow{2}{*}{ Remarks } \\
\hline & & & & & \\
\hline 1 & Receive Ticket Information & $\sqrt{ }$ & $\sqrt{ }$ & $\sqrt{ }$ & Ticket Status Update \\
\hline 2 & Provide descriptive info about the problem & & & $\sqrt{ }$ & Issue Tracker \\
\hline 3 & Ask for details or Verify problem before acting & $\sqrt{ }$ & & & Issue Log \\
\hline 4 & Analyze Problem/Issues & $\sqrt{ }$ & $\sqrt{ }$ & & Problem Analysis Doc \\
\hline 5 & $\begin{array}{l}\text { Get in touch with SME/L3 with suggested } \\
\text { alternatives }\end{array}$ & $\sqrt{ }$ & $\sqrt{ }$ & & $\begin{array}{l}\text { Provide different } \\
\text { approaches to Issues }\end{array}$ \\
\hline 6 & Develop Fix and Communicate outcome & $\sqrt{ }$ & $\sqrt{ }$ & & If NOT GO TO Step 12 \\
\hline 7 & Test the fix & $\sqrt{ }$ & $\sqrt{ }$ & & \\
\hline 8 & Create functional test scripts & $\sqrt{ }$ & & & \\
\hline 9 & Carry out Functional test and enter results & & $\sqrt{ }$ & & \\
\hline 10 & Update Issue Log Status & $\sqrt{ }$ & $\sqrt{ }$ & & Issue Log Status \\
\hline 11 & Try Work Around or Re-run or Invoke new request & $\sqrt{ }$ & & $\sqrt{ }$ & KT doc \\
\hline 12 & Close loop with Users Concerned & & $\sqrt{ }$ & $\sqrt{ }$ & Update Ticket Status \\
\hline 13 & $\begin{array}{l}\text { Monitor Production Stability with Fix or Work } \\
\text { Around/Monitor Re-run }\end{array}$ & $\sqrt{ }$ & $\sqrt{ }$ & $\sqrt{ }$ & Update Test Document \\
\hline
\end{tabular}


2) Service Asset and Configuration Management

The service provider tracks and reports the value and ownership of financial assets (asset management) throughout their service life.

For the case under study the asset management is not in scope as the assets for this project are directly managed by the client.

Configuration Management tracks, using a Configuration Management system, the Configurable Items (CIs) of an IT System. CIs are the organizational elements that are used in the provision and management of IT services. Hardware, software, documentation, and personnel information that the IT Services are dependent on are also tracked as part of configuration management.

An open source tool named Tortoise SVN is used for this project. Tortoise SVN is easy to use software with features such as Revision control, version control and source control. All the CIs for this case are maintained in this tool, which includes all the processes, source code, with version control features. Configuration audit is done through an Audit checklist.

3) Release and Deployment Management

Release and Deployment Management is the process during which service providers prepare services for release into the production environment. This includes the building, testing, and delivery of the service in an effort to provide the customer with expected results. During this process, the new or changed services are moved into Service Operations.

4) Knowledge Management

Knowledge Management is the process that service providers use to collect, analyse, and exchange information and knowledge within the organization. The Knowledge management system stores the information and knowledge and allows it to be shared among the IT organization, its partners, and customers. This system helps the support team for avoiding redundant tasks arising out of similar issues observed or resolved in the past.

\subsubsection{Service Operation}

The major tasks involved in the Level 2 support for the scope of the case are:

- Help users on failures/errors, basic transactions, helping with "how to" and "what if" questions, by identifying issues thru monitoring and interaction with users managing/handling the functional needs.

- Assess and fix/resolve (conditionally) the errors related to Interfaces.

- Co-ordinate with MIS and other Support groups for data errors.

- Guide the end users and support them.

- Monitor scheduled jobs or transactions.

- Monitorthe processes and provide feedback to users.

Table 5 provides a high level approach to the Level 2 Support undertaken as part of this project as agreed upon by us with the customer.

\subsubsection{Continual Service Improvement}

Continual Service Improvement phase (CSI) is responsible for continually aligning IT services to changing business needs. CSI identifies and implements improvements to IT services that support business processes. These improvement activities support the lifecycle approach through Service Strategy, Service Design, Service Transition, and Service Operation. In effect, CSI is about looking for ways to improve process efficiency and cost effectiveness throughout the entire service lifecycle.

Service Improvement is where the service provider maintains and improves the quality of the service by agreeing to, monitoring, and reporting on IT achievements. This process can be initiated by a service review and is responsible for creating a service improvement plan.

The continuous improvement in the present case is attempted through an integrated Lean Six Sigma framework.

Lean Six Sigma enabled defect reduction in the ticket handling process. This has been achieved through the analysis of the collected data available in the ticket handling tool, major errors in the process has been identified and corrected, and repetition of such errors are controlled. Table 6 depicts the analysis of the defects for the number of tickets handled from September 2012 to January 2013. The Defects per million opportunities (DPMO) is an indicative statistical value which is being used to calculate the Sigma levels. The overall improvement in the Sigma values is given in Table 7. 
Table 5. Approach to level 2 support.

\begin{tabular}{|c|c|c|c|c|}
\hline Sl. No. & Proposed Tasks/Activities & By L2 Team & By Customer & Deliverables \& Sample Templates \\
\hline & Functional: & $\square$ & $\square$ & \\
\hline 1 & Check Configuration & $\square$ & & Configuration Testing Doc \\
\hline 2 & Review the Configuration & $\square$ & $\square$ & Configuration Review \\
\hline \multirow[t]{2}{*}{3} & Document the Settings & $\square$ & $\square$ & Approved Configuration Docs \\
\hline & Problem Analysis: & & & \\
\hline 4 & Study Typical Issue list & $\square$ & & Get a feel for problems \\
\hline 5 & $\begin{array}{l}\text { Talk to Users/SMEs and check out } \\
\text { sample solution workarounds/fixes }\end{array}$ & $\square$ & & $\begin{array}{l}\text { List of Solution possibilities } \\
\text { and Case dB enlisting }\end{array}$ \\
\hline \multirow[t]{2}{*}{6} & Get Approval/Test for completion & $\square$ & $\square$ & Approval Doc \\
\hline & Problem Resolution: & & & \\
\hline 7 & Recommend alternatives or fix bug & $\square$ & & Issue analysis document \\
\hline 8 & Make the Fix & $\square$ & & $\begin{array}{l}\text { List of Solution possibilities } \\
\text { and Case dB enlisting }\end{array}$ \\
\hline 9 & Verify and Validate Fix & $\square$ & & Validate Fixes \\
\hline 10 & Check with Users and capture results & $\square$ & & Document solution and results \\
\hline \multirow[t]{2}{*}{11} & Get Approval & $\square$ & $\square$ & Approval Doc \\
\hline & Other issues: & & & \\
\hline 12 & $\begin{array}{l}\text { Analyze the Interface issues } \\
\text { \& Data related errors }\end{array}$ & $\square$ & & Issue analysis document \\
\hline 13 & Make the desired changes & $\square$ & & $\begin{array}{l}\text { List of Solution possibilities } \\
\text { and Case dB enlisting }\end{array}$ \\
\hline 14 & Verify and Validate the change & $\square$ & & Validate Fixes \\
\hline 15 & Check with Users and capture results & $\square$ & & Document solution and results \\
\hline \multirow[t]{2}{*}{16} & Get Approval & $\square$ & $\square$ & Approval Doc \\
\hline & Issue Closure: & & & \\
\hline 17 & Check Output with Users & $\square$ & $\square$ & User Confirmation—Doc/E-MAIL \\
\hline 18 & Document Results & $\square$ & & Unit Testing Results \\
\hline 19 & $\begin{array}{l}\text { Describe Problem and Solution } \\
\text { with Users' comments }\end{array}$ & & $\square$ & Respective Document \& Case dB enlisting \\
\hline 20 & Collect Performance data & $\square$ & $\square$ & User Confirmation/Print outs \\
\hline 21 & Collate Issue Logs \& Tickets closed & $\square$ & & Ticket Logs \\
\hline \multirow[t]{2}{*}{22} & Submit Closure Report & & & Periodic Reports \\
\hline & Monitoring: & & & \\
\hline 23 & Monitoring Scheduled Jobs & $\square$ & & Job failure notifications \\
\hline
\end{tabular}


Table 6. Sigma values.

\begin{tabular}{|c|c|c|c|c|c|}
\hline \multicolumn{6}{|c|}{ Month: Sep 2012} \\
\hline & $\mathbf{P 1}$ & P2 & P3 & P4 & Overall \\
\hline No. of tickets & 24 & 35 & 180 & 140 & 379 \\
\hline \# of defects & 8 & 5 & 11 & 13 & 37 \\
\hline Yield (\%) & 66.7 & 85.7 & 93.9 & 90.7 & 90.2 \\
\hline DPMO & $333,333.33$ & $142,857.14$ & $61,111.11$ & $92,857.14$ & $97,625.33$ \\
\hline Sigma Level & 1.93 & 2.57 & 3.05 & 2.82 & 2.8 \\
\hline \multicolumn{6}{|c|}{ Month: Oct 2012} \\
\hline & P1 & $\mathbf{P 2}$ & P3 & $\mathbf{P 4}$ & Overall \\
\hline No. of tickets & 12 & 67 & 164 & 120 & 363 \\
\hline \# of defects & 3 & 8 & 7 & 5 & 23 \\
\hline Yield (\%) & 75 & 86.76 & 95.73 & 95.83 & 93.66 \\
\hline DPMO & 250,000 & $119,402.99$ & $42,682.93$ & $41,666.67$ & $63,360.88$ \\
\hline Sigma Level & 2.17 & 2.68 & 3.22 & 3.23 & 3.03 \\
\hline \multicolumn{6}{|c|}{ Month: Nov 2012} \\
\hline & P1 & $\mathbf{P 2}$ & P3 & P4 & Overall \\
\hline No. of tickets & 31 & 30 & 150 & 141 & 352 \\
\hline \# of defects & 4 & 3 & 3 & 4 & 14 \\
\hline Yield (\%) & 87.1 & 90 & 98 & 97.16 & 96.02 \\
\hline DPMO & $129,032.26$ & 100,000 & 20,000 & $28,368.79$ & $39,772.73$ \\
\hline Sigma Level & 2.63 & 2.78 & 3.55 & 3.41 & 3.25 \\
\hline \multicolumn{6}{|c|}{ Month: Dec 2012} \\
\hline & $\mathbf{P 1}$ & $\mathbf{P 2}$ & P3 & P4 & Overall \\
\hline No. of tickets & 29 & 21 & 120 & 37 & 207 \\
\hline \# of defects & 2 & 1 & 2 & 1 & 6 \\
\hline Yield (\%) & 93.1 & 95.24 & 98.3 & 97.3 & 97.1 \\
\hline DPMO & $68,965.52$ & $47,619.05$ & $16,666.67$ & $27,027.03$ & $28,985.51$ \\
\hline Sigma Level & 2.98 & 3.17 & 3.63 & 3.43 & 3.4 \\
\hline \multicolumn{6}{|c|}{ Month: Jan 2013} \\
\hline & P1 & $\mathbf{P 2}$ & P3 & P4 & Overall \\
\hline No. of tickets & 16 & 29 & 117 & 93 & 255 \\
\hline \# of defects & 1 & 1 & 1 & 2 & 5 \\
\hline Yield (\%) & 93.75 & 96.55 & 99.15 & 97.85 & 98.04 \\
\hline DPMO & 62,500 & $34,482.76$ & 8547.01 & $21,505.38$ & $19,607.84$ \\
\hline Sigma Level & 3.03 & 3.32 & 3.88 & 3.52 & 3.56 \\
\hline
\end{tabular}


Table 7. Overall sigma values.

\begin{tabular}{cccccc}
\hline & P1 & P2 & P3 & P4 & Overall \\
\hline No. of tickets & 24 & 35 & 180 & 140 & 379 \\
\# of defects & 8 & 5 & 11 & 13 & 37 \\
Yield (\%) & 66.7 & 85.7 & 93.9 & 90.7 & 90.2 \\
DPMO & $333,333.33$ & $142,857.14$ & $61,111.11$ & $92,857.14$ & $97,625.33$ \\
Sigma Level & $\mathbf{1 . 9 3}$ & $\mathbf{2 . 5 7}$ & $\mathbf{3 . 0 5}$ & $\mathbf{2 . 8 2}$ & 2.8 \\
\hline
\end{tabular}

Figure 1 shows the improvement in Sigma values after implementing Lean Six Sigma over ITIL for the support scenario under study.

The implementation of ITIL process is reviewed for identification of the non-value added activities within the process through Lean methodology.

The non-value added activities identified through in the current process are:

- The issue logging were done through a Voice call and email for the same issue. This was consuming more time.

- The tickets were logged into an excel sheet for tracking. There were different versions of excel sheet which was confusing for the application support team.

This has in turn resulted in reduction of the team size. The overall team size is reduced from 33 to 27, without compromising the service levels across the modules. Table 8 shows the reduction in the support team size across modules helping reducing the cost of operations.

\section{Summary of Results}

With the implementation of Lean Six Sigma for ITIL service delivery for the case under study, there has been a significant improvement in Sigma Levels depicting the reduction in the defects. This has been achieved through a process which is Lean in nature.

The most distinctive characteristic of using Lean Six Sigma for ITIL Service delivery is its bottom-up approach to process improvement. Lean Six Sigma makes the process more efficient, removing waste from the process and, ultimately, requiring fewer financial resources to maintain the improved IT function. The impact of Lean Sixma in ITIL Service delivery on the bottom line can be significant, freeing precious budget resources that can then be applied to the agency's critical missions. Simply put, integrating Lean Six Sigma is a continuous process improvement model and aligns with the objective of ITIL framework that becomes a self-fulfilling entity.

The added focus on resource utilization to identify opportunities to improve process efficiencies and reduce costs ultimately frees up precious financial resources that can be applied directly to the organization's primary mission - which should be the ultimate goal of every function within the organization. There is a financial saving of US\$288K annually through this implementation. This could be achieved through eliminating wastes and reducing defects through minimizing process variation.

\section{Conclusions}

At first glance, ITIL and Lean Sigma appear to be mutually exclusive. However, as this paper discusses and the GE ITSM improvement project validates, these two approaches are highly complementary and can be used in combination effectively to continually improve business processes. The benefits are compelling:

- Reduce costs by helping to minimize potential downtime and the adverse effects of system, network, and application failures and install, move, add, change and decommission implementations.

- Enhance decision-making ability by facilitating access to information throughout the organization, and by enabling the enterprise wide use of outputs from an integrated framework of processes and tools through such devices as cross functional IT service dashboards. 


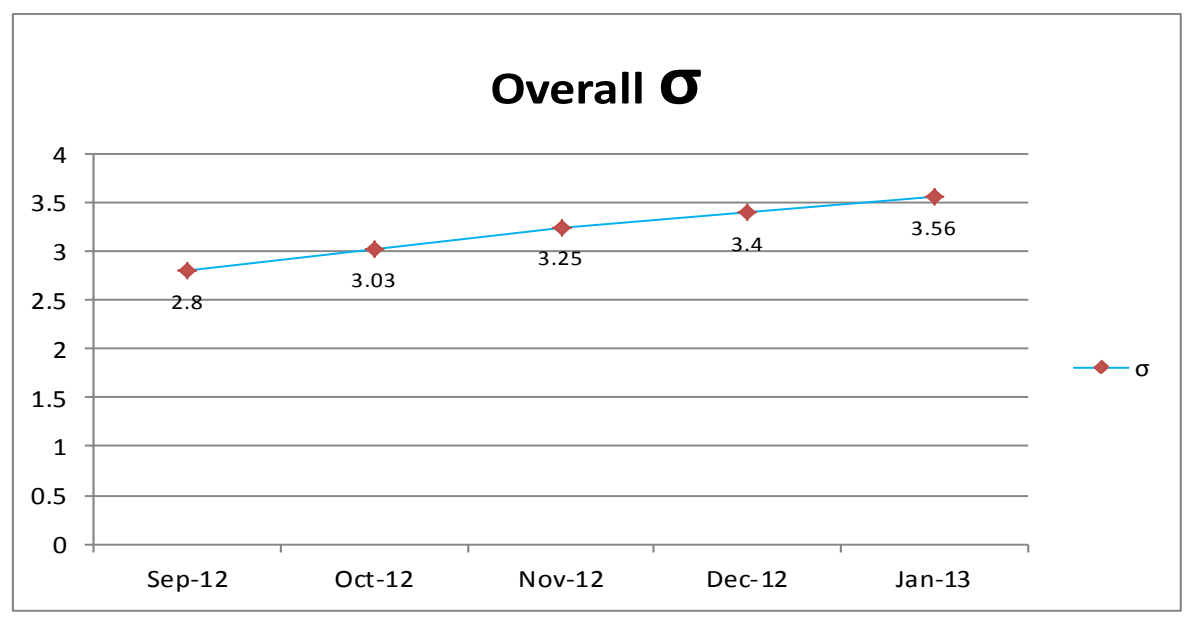

Figure 1. Improvement of Sigma value.

Table 8. Current support team.

\begin{tabular}{|c|c|c|}
\hline Module & Coverage & Team Size \\
\hline $\mathrm{SD} / \mathrm{MM}$ & $\begin{array}{l}24 \times 5 \text { weekdays } \\
16 \times 2 \text { weekends }\end{array}$ & 11 \\
\hline PP & $16 \times 7$ & 7 \\
\hline $\mathrm{FI} / \mathrm{CO}$ & $16 \times 5$ & 6 \\
\hline $\mathrm{ABAP}$ & $16 \times 5$ & 3 \\
\hline \multicolumn{2}{|c|}{ Total } & 27 \\
\hline
\end{tabular}

- Improve IT service levels by creating operational efficiencies and enabling a linked ITSM process loop for defining, measuring, analyzing, improving, and controlling service performance.

However, there is not much of research findings reported its repetitiveness across ITSM.

\section{References}

[1] George, M. (2003) Lean Six Sigma for Service: How to Use Lean Speed and Six Sigma Quality to Improve Services and Transactions. McGraw-Hill, New York.

[2] Parasuraman, A., Zeithaml, V. and Berry, L. (1984), A Conceptual Model of Service Quality. Marketing Science Institute, Cambridge.

[3] Van Bon, J., Pieper, M., and Annelies van der, V. (2006) Foundations of IT Service Management, Based on ITIL. itSFM-NL.

[4] Su, C.-T., Chiang, T.-L. and Chang, C.-M. (2006) Improving Service Quality by Capitalizing on an Integrated Lean Six Sigma methodology. International Journal of Six Sigma and Competitive Advantage, 2, 1-22. http://dx.doi.org/10.1504/IJSSCA.2006.009367

[5] Peynot, R. (2006) Firms must take ITIL Beyond IT Operational Goals-Service Providers Can Help with Change Management Issues. Forester.

[6] Salle, M. (2004) IT Service Management and IT Governance: Review, Comparative Analysis and their Impact on Utility Computing, 2004. HP Laboratories Palo Alto Trusted Systems Laboratory. http://www.hpl.hp.com/techreports/2004/HPL-2004-98.pdf

[7] Humphrey, W. (1989) Managing the Software Process, Addison-Wesley, Reading, MA. InformationWeek (2003) Software quality, InformationWeek.

[8] Pigoski, T.M. (1997) Practical Software Maintenance-Best Practices for Managing Your Software Investment. John Wiley \& Sons, New York, 356.

[9] Quinn, J. and Gagnon, C. (1986) Will Services Follow Manufacturing into Decline? Harvard Business Review, 95-103. 
[10] Zeithaml, V., Parasuraman, A. and Berry, L. (1990) Delivering Service Quality. The Free Press, New York.

[11] Allway, M. and Corbett, S. (2002) Shifting to Lean Service: Stealing a Play from Manufacturers'Playbooks. Journal of Organisational Excellence, 21, 45-54. http://dx.doi.org/10.1002/npr.10019

[12] Lino, A. and da Sila, M.M. (2009) Improving ITIL Processes Using a Lean Methodology. andre.m.lino@ist.utl.pt, mms@ist.utl.pt

[13] Chan, P.C., Durant, S.R., Mae Gall, V. and Raisinghani, (2009) Aligning Six Sigma and ITIL to Improve IT Service Management. International Journal of E-Services and Mobile Applications, 1, 62-82.

[14] Pillai, A.K.R., Pundir, A.K. and Ganapathy, L. (2012) Implementing Integrated Lean Six Sigma for Software Development: A Flexibility Framework for Managing the Continuity-Change Dichotomy. Global Journal of Flexible Systems Management, 13, 107-116.

[15] Fry, M. and Bolt, M. (2004) Combining ITIL ${ }^{\circledR}$ and Six Sigma to Improve Information Technology Service Management at General Electric.

[16] Reiner, L. (2007) ABC: An Introduction to the IT Infrastructure Library. CIO.com

[17] Betz, C.T. (2007) Architecture and Patterns for IT Service Management, Resource Planning, and Governance: Making Shoes for the Cobbler's Children. Morgan Kaufmann Publishers, San Francisco, 4-5.

[18] Fillingham, D. (2008) Making Lean Thinking Work in the NHS. Health Service Journal, 3.

[19] Sayer, N.J. and Williams, B. (2008) Lean for Dummies. Wiley Publishing, Hoboken, 2008.

[20] Su, C.-T. and Kano, N. (2003) A Comparison of TQM and Six Sigma. Proceedings of the 33rd JSQC Conference, Nagoya, 15 November 2003, 15-18.

[21] Reichheld, F.F. and Sasser Jr., W.E. (1990) Zero Defections: Quality Comes to Customer Service. Harvard Business Review, 68, 105-111.

[22] Harry, M. and Schroeder, R. (2000) Six Sigma: The Breakthrough Management Strategy Revolutionizing the World's Top Corporations. Doubleday, New York.

[23] Breyfogle, F.W. (1999) Implementing Six-Sigma—Smarter Solutions Using Statistical Methods. John Wiley \& Sons, Inc., New York.

[24] Hoerl, R. (2004) One Perspective on the Future of Six-Sigma. International Journal of Six Sigma and Competitive Advantage, 1, 112-119. http://dx.doi.org/10.1504/IJSSCA.2004.005281

[25] Damiano, F. and McLauglin, K. (2007) American ITIL, New York, NY. Retrieved November 30 from ACM Digital Library.

[26] Arnheiter, E.D. and Maleyeff, J. (2005) The Integration of Lean Management and Six Sigma Lally School of Management \& Technology. Rensselaer Polytechnic Institute, Hartford.

[27] Thomas, A., Barton, R. and Chiamaka, C. (2009) Applying Lean Six Sigma in a Small Engineering Company-A Model for Change. Journal of Manufacturing Technology Management, 20, 113-129. http://dx.doi.org/10.1108/17410380910925433

[28] Tourniaire, F. and Farrell, R. (1996) The Art of Software Support. Prentice Hall, Upper Saddle River.

[29] Jarzabek, S. (2007) Effective Software Maintenance and Evolution: A Reuse-Based Approach. Auerbach Publications, Boca Raton. 